\title{
ERGONOMICALLY DESIGNED WORKSTATION BASED ON SIMULATION OF WORKER'S MOVEMENTS
}

\author{
Fulder, T.; Pizmoht, P.; Polajnar, A. \& Leber, M. \\ University of Maribor, Faculty of Mechanical Engineering, Smetanova 17, 2000 Maribor, Slovenia \\ E-mail: tatjana.fulder@uni-mb.si; petja.pizmoht@uni-mb.si; \\ andrej.polajnar@uni-mb.si; marjan.leber@uni-mb.si
}

\begin{abstract}
An ergonomics approach to the design of an industrial workstation attempts to achieve an appropriate balance between worker's capabilities and work requirements to optimize workers' productivity and the total system, as well as provide workers' physical and mental well-being, job satisfaction and safety. Over the years many theories, principles, methods and data relevant to the workstation design have been generated through research in ergonomics. Much of this knowledge is integrated in the software computer package ERGOPlan. The paper presents an optimal ergonomically and economically designed workstation of a cutter which was built with the use of two ERGO modules, ERGOMas (workstation design) and ERGOMan (simulation of workers' movements). To incorporate economic aspect of the workstation design, we parametrically described the key dimensions of the workstation. This action enabled optimal workstation design with consideration of both aspects.
\end{abstract}

Key Words: Workstation Design, Ergonomics, Simulation, Static and Dynamic Analysis

\section{INTRODUCTION}

According to literature, a large number of procedures for the design and planning of manual workstations have been developed [1, 2]. An important planning step in these procedures is the selection of part and tool bins and their arrangements in the workstation with economic and ergonomic considerations. All these procedures are general and they do not include rules or other detailed information about how to carry out these steps [1].

The design of industrial workstations, as with most forms of design, is iterative and highly interactive. The designer has to consider numerous constraints and solutions for contradictory goals [3]. Edward [4] developed an MTM-based task time prediction (TTP) model and a biokinematic human model for workstation design. A computer-aided tool and different simulations can greatly assist the planning engineer in this complex and time-consuming job. However, a large number of conflicting constraints make it impossible to find the optimal solution procedure. Thus, heuristic techniques have to be used [1].

There have been several computer-aided systems developed for the design and planning of manual workstation or manual assembly workstations, which can be classified into three categories: human modelling, furniture selection, and bins and tools selection and placement. Human models can be used for corrective redesigning of workstations [5, 6]. The design process remains with the planning engineer while the scrutiny of the solution with regard to anthropometry and biomechanics can be done with the help of human models. Systems for selecting furniture $[7,8,9]$ and choosing and placing bins and tools $[10,11]$ should consider both economic and ergonomic goals. However, most of these systems can only be used interactively [12].

Braun et. al [1] reported a computer-aided planning system (EMMA) for designing and planning manual assembly systems, which is constructed from AutoCAD and offers all the 
functions needed to simulate and record the assembly process. It is claimed that workstation layouts can be designed and evaluated with both ergonomic (human factors) and economic (assembly time and cost, MTM time analysis) considerations.

What is ergonomic workstation design?

\section{ERGONOMIC WORKSTATION DESIGN}

A workstation may be defined as a place within the workplace where equipment or instrumentation is positioned in such a convenient way that users can perform their tasks properly [13, 14]. Workstation design deals with choosing and arranging equipment, machinery, tools, and accommodations for users so that workflow and organization are optimized. Workstation design is the object of several recent developments in ergonomics, particularly regarding increasing level of competition and technological development in modern enterprise environments; see $[14,15,16]$ among others. In the design of workstations, designers are often faced with the task of eliciting components to be included in the project. Workstation components (WCs) may be divided into two major groups [2]: a) functional, such as work seats, worktables, machinery, and accessories, and b) environmental, related to psychological, social, and climatic inputs that affect worker's behavior. The best choice takes into consideration ergonomic criteria, such as anthropometric and biomechanical characteristics, and commercial criteria, such as warranty length and service level provided by manufacturers.

Das and Grady [17] provided a list of structural dimensions (body size) they considered important in the design of industrial workstations. Their dimensions were developed according to systematic changes to the data of Hertzberg [18]. These dimensions are useful in the determination of clearance and general height parameters of the workstation. However, knowledge of the normal reach area and the 3-D reach volume are also important in the design process. Dimensions of the normal reach area (NRA) have been presented by several authors [19, 20, 21, 22]. Typically the NRA dimensions are presented as 5th, 50th and 95th percentile curves. In theory, using the 5th percentile curve results in a design within which the majority (95 \%) of operators could comfortably perform the intended tasks. Sengupta and Das [23] recently provided the reach dimensions of the $5^{\text {th }}, 50^{\text {th }}$ and $95^{\text {th }}$ percentile for male and female operators during seated and standing work.

To conceptualize and finalize the design ideas, manual drafting has been replaced currently by computer aided design (CAD) technology because it is more productive and accurate. Starting in the mid-seventies, several CAD based human modelling programs have emerged to aid workstation designers. These programs contain one or more anthropometric databases. They enable users to generate three dimensional (3D) graphic images of human models on the computer video display terminal (VDT). By using these programs, the human-machine compatibility can be analyzed visually as well as objectively through various programmed outputs.

Due to the complexity of human-machine modelling in ergonomics, many kinds of individual intelligent techniques such as knowledge-based (expert) system, ERGO-SPEC [1], neural network [24, 25] and fuzzy logic have been used for the analysis and prediction of working postures of human operators in manual-handling tasks and the design/layout of workstations and tasks. The literature has been reviewed by Zha, Lim, and Fok [26]. For proper evaluation of the interactions between the operator and the workstation through human-machine modeling, the accurate prediction of the human reach or handling loads is one of the essential functions of those models. In postural analysis and prediction of manual handling loads, expert or knowledge-based systems have also been used, such as in LIFTAN [27], and ERGON-EXPERT [28]. 
To help in the design or redesign of a workstation it would be helpful to know in advance the postural stress consequences of a wide range of body postures.

Postural analysis tools have been shown to be a valuable technique for reducing injuries and increasing productivity in industry. One of them is the Ovako Working-posture Analysing System (OWAS) [29]. OWAS is one of a number of postural measurement systems proposed by ergonomists. The purpose of OWAS is to provide a system for analyzing and classifying working postures with the aim of developing working methods consistent with the promotion of occupational health. Subsequent uses of OWAS have included: planning new jobs, purchasing equipment that will allow safe postural usage, job placement for personnel and production improvement. There were three criteria used in creating the OWAS. First, it had to be usable by persons whose training is not specifically in ergonomics. Second, it was required to give non-oversimplified but still unambiguous results, and third, it had to possibilities for correcting oversimplified ergonomics information. The success of OWAS is a result of several factors including applicability, validity, and reliability. The versatility of its posture coding components provides applicability to most working postures.

\section{METHODOLOGY AND PROBLEM SETTING}

In one of the oldest industries, the textile industry, the textile operations have been ergonomically studied extensively and many workstation standards exist.

There are numerous health and safety issues associated with the textile industry. They include: chemical exposure from the processing and dyeing of materials, exposure to cotton and other organic dusts, musculoskeletal stresses, and noise exposure.

Mahone [30] noted that $70 \%$ of sewing machine operators using foot controls report back pain, $35 \%$ report persistent low back pain, $25 \%$ have suffered a compensable cumulative trauma disorder (CTD) and $49 \%$ of workers experience pain in the neck. So hand sewing and trimming are stressful to all upper limbs, stitching tasks are associated with pain in the shoulders, wrists and hands, ironing by hand is associated with elbow pain, garment assembly tasks are associated with CTDs of the hands and wrists and foot operated sewing is associated with pain in the back.

Because of these facts we decided to analyse and ergonomically design the workstation of a cutter in a Slovenian textile company.

The cutting process is performed on worktable with a tape cutter. The tape cutter is fixed, only material has to be transported. The worker (in our case a female) is in standing position. The cutting process could be described in following steps: from the starting-point, the worker first turns left and then reaches for rough cut layer which has to be cut clear, then she leads this cut layer in the area of the tape cutter where the cutter process is performed, and at the end she puts the finished parts on the take-off table. The process is repeated afterwards. We can notice some wrong postures of back and head, and the movement of both upper arms leads to shoulder injury.

The analysis shows that it is necessary to design this workstation ergonomically, to prevent permanent worker's injuries. We used anthropological characteristics which demand a sistematical approach to problem solution.

For the analysis and new workstation design the software package ERGOPlan was used.

The ERGOPlan-process chain integrates the complete planning- and production process from preliminary planning on the basis of product structure through concept and design of production systems to regular plant operations. This computer software package enables formal, egonomic, cost and time workstation analysis. It contains several modules; for workstation design ERGOMas and ERGOMan are used. 
ERGOMas creates 3D-layouts, bills of materials and time analysis. Balancings of production lines are generated and ergonomic workstation design is ensured. Planning times and costs are thus reduced, expensive errors in product design prevented. ERGOMan simulates worker movements, evaluates working postures and determines maximum loads for any position of the human body. Collisions are detected, loads on joints calculated and MTMI-Analyses are generated.

\subsection{Existent workstation}

The workstation consists:

- a tape cutter,

- a worktable and

- a take-off table (Fig. 1).

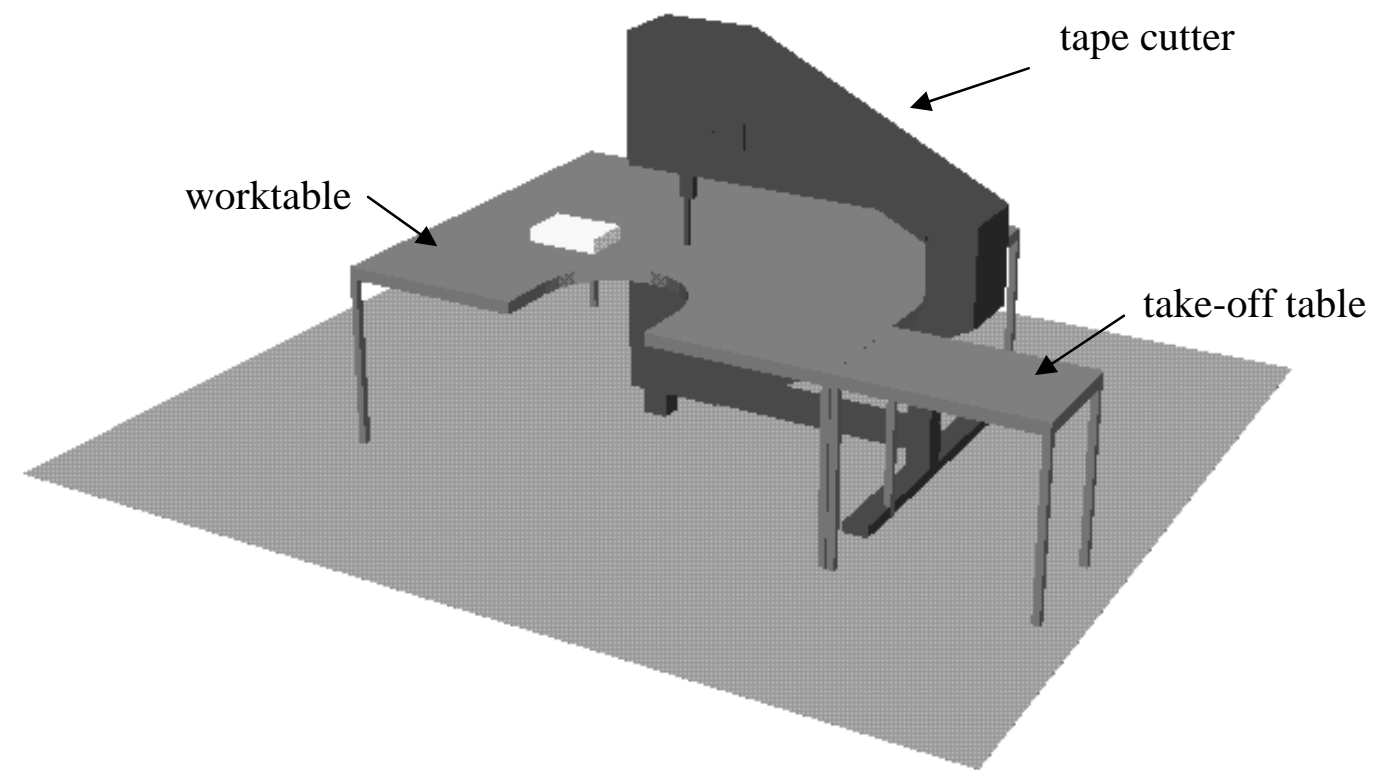

Figure 1: Existent workstation.

The analysed workstation is organised for standing work. The work area where the worker is standing has an opening $590 \times 540 \mathrm{~mm}$. This makes easier access and easier transportation of cut layers in the area of the tape cutter. The worktable and take-off table heights are 750 $\mathrm{mm}$ and the take-off table is placed on the right side of the worktable.

First we performed the static analysis for $50^{\text {th }}$ percentile reach dimensions for female operator and standing work. We analysed the reach area and the field of vision. The results clearly showed that the worktable height is too low. The field of vision, because of the posture of the head $\left(40^{\circ}\right)$, is completely inappropriate and the reach area is outside of the tape cutter's area.

Then we performed the dynamic analysis which is based on the OWAS method. The results show that almost $50 \%$ of all workers' movements are in the yellow area which shows abnormal body postures (Fig. 2) what has to be changed. 


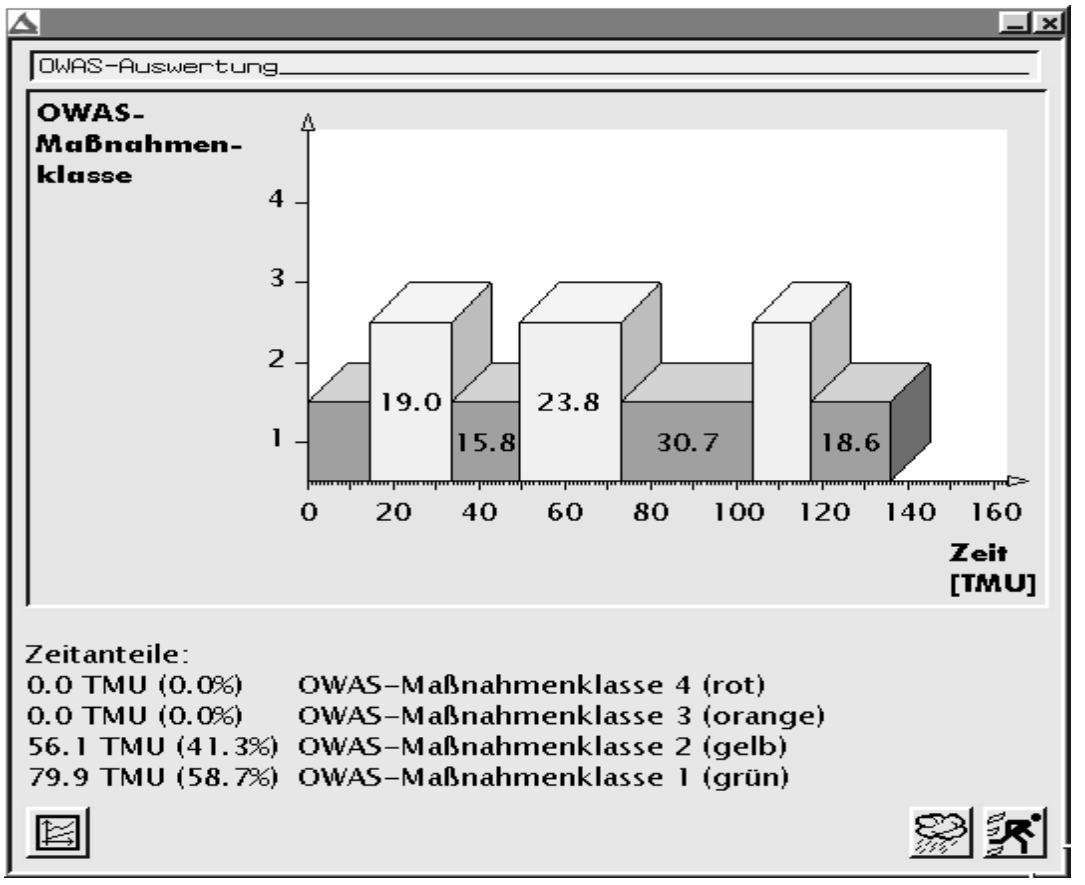

Figure 2: Results of OWAS analysis.

The presented analysis is one of the several we performed. Static (the reach area and field of vision) and dynamic (OWAS) simulations for $5^{\text {th }}$ and $95^{\text {th }}$ percentile female and male operators by changeable height of the workstation are also been made. The economical aspect of the ergonomically designed workstation brought us to the idea of parametrically described workstation key dimensions. On the basis of defined variants (tests plan) we performed the necessary simulations, where we estimated two fundamental values (time value and loading). This procedure results in optimal designed workstation (by the defined conditions), considering the ergonomical and the economical aspect.

\section{RESULTS}

Based on former results we designed the ergonomically optimal workstation which is appropriate for the reach dimensions of the $5^{\text {th }}, 50^{\text {th }}$ and $95^{\text {th }}$ percentile and for female and male operators.

The workstation consists:

- a tape cutter,

- an integrated worktable,

- a shelf for cut layers,

- a container for redundant material and

- a chair (Fig. 3).

The workstation is adjusted to the constitution of the human body, body sizes and body movements. The worktable is flexible meaning different heights and inclinations of the work area. This solution prevents the inappropriate inclination of the neck spine and it is good for the general state of health. The worktable is designed to assure comfort and pleasant working conditions which contributes to lower psychophysical loads. The optimized workstation also prevents inappropriate physiological body postures and partial loads. 
The part of the worktable behind the tape cutter has an extra component with the possibility of inclination. This component serves for easier transportation of redundant material. The inclination of the worktable does not represent a problem at leading cut layers because there is an airbag which stabilizes fabric layers. The inclination of the worktable requests a specific construction of the flexible tape cutter because it has to be adjustable regarding worktable inclination.

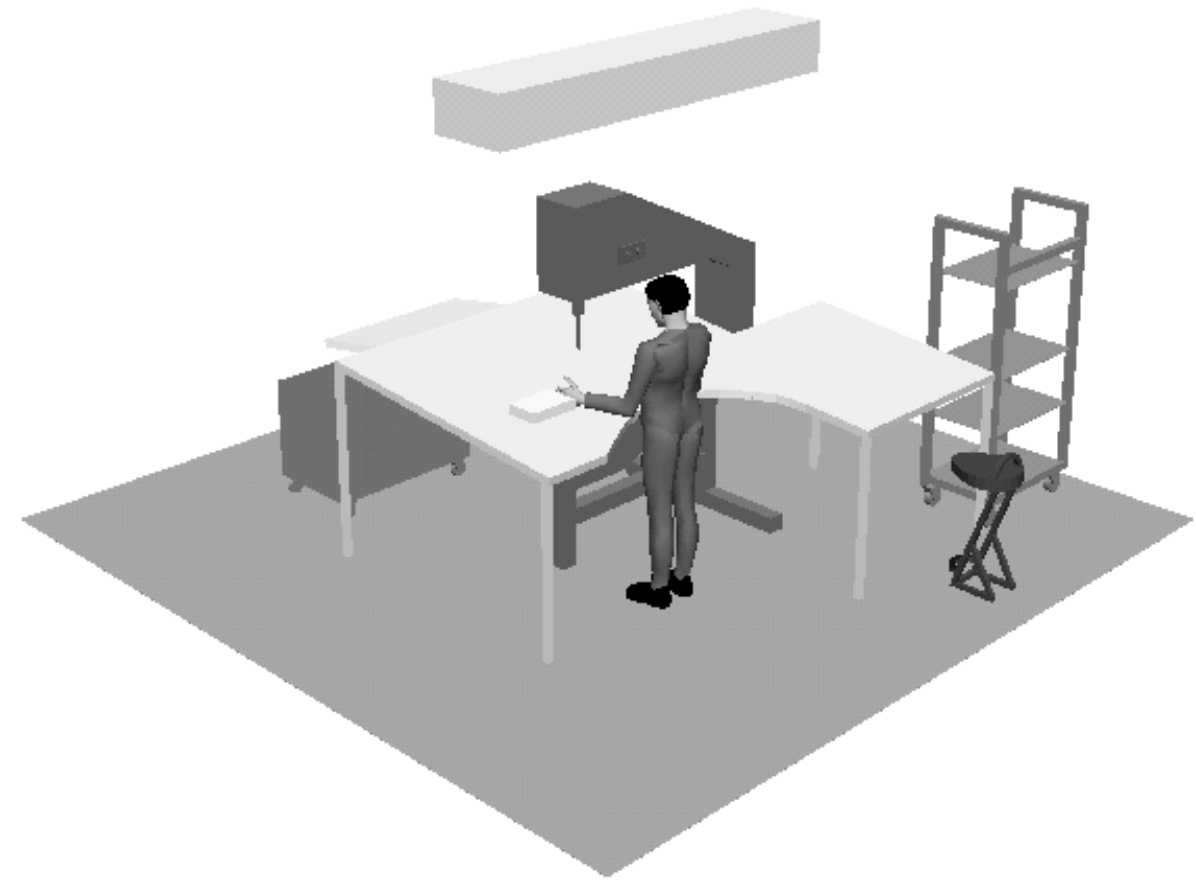

Figure 3: Ergonomically designed workstation.

The adequacy of the workstation was conformed by both, static and dynamic analyse. The results of the OWAS analysis of worker's movements showed that all movements or all body postures are in the optimal green area (Fig. 4). So the results confirmed the fact that this workstation is ergonomically optimized.

\section{CONCLUSION}

In designing workstations, conventional methods of evaluating human-machine compatibility involved the use of flat card board manikins along with layout drawings, or the construction of mockup workstation with evaluation by live subjects. These procedures are expensive, time consuming and are usually performed at a later stage of design. Because of these facts, the simulation based analysis of the present or new workstation design and body postures is an effective way of solving these problems, what is presented in this paper. The used sotfware package ERGOPlan enables fast and efficient optimization of workstations, but the user has to have a lot of experience and knowledge in the field of ergonomics and ergonomical workstation design. The user interface is also not specifically user-friendly. This package also enables testing of different variants of workstations (modul ERGOMas) and body movements (ERGOMan) what results in an efficient and economic way of analysing. This is very positive characteristic because the optimal design of workstation requests system approach. 


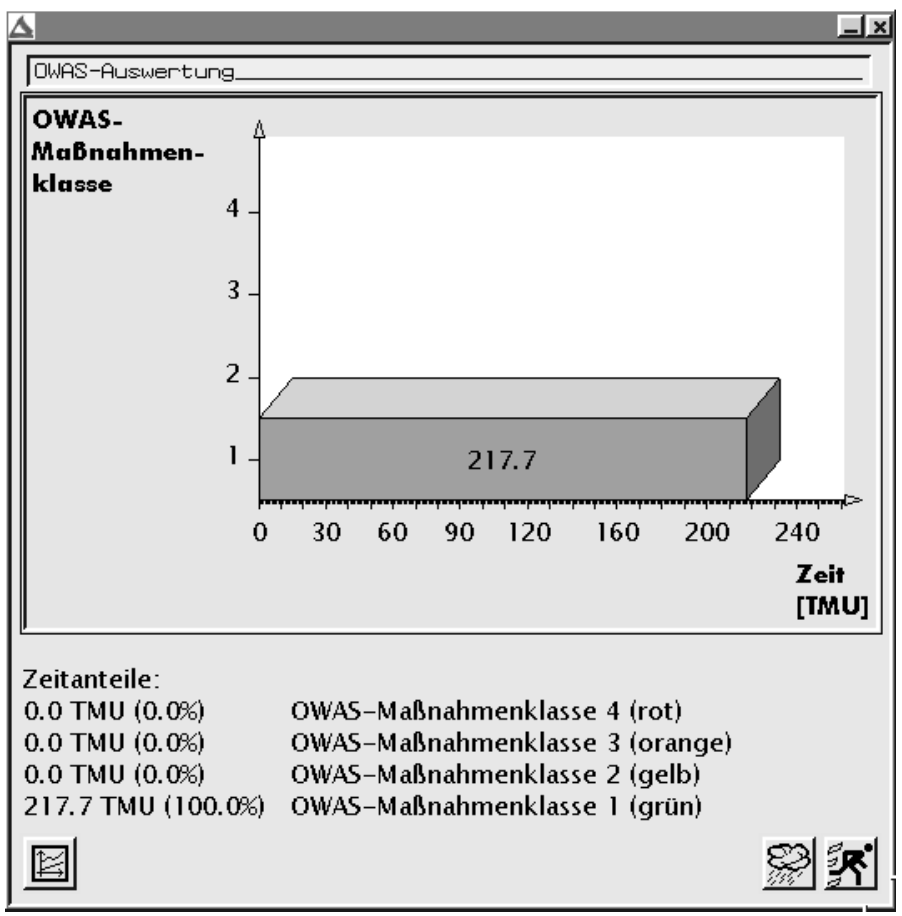

The time value icreased from 136 TMU in existing workstation to 217 TMU in optimized system because of the change in the work extent.

Figure 4: OWAS analysis of ergonomically designed workstation.

That means we have to be familiar with the working task. In other words, it is important to understand the tehnological process and the requirements but we can't forget the economic aspect of the project. The parametrically described key dimensions of the analysed workstation enable the optimal design of the workstation from both economical and ergonomical aspects.

We can also conclude that computer aided workstation design has potencial, but only when software is used by skilled and experienced people with a lot of knowledge about ergonomical design.

\section{REFERENCES}

[1] Braun, W. J.; Reboller, R.; Schiller, E. F. (1996). Computer aided planning and design of manual assembly systems, International Journal of Production Research, Vol. 34, No. 8, 2317-2333

[2] Bullinger, H. J. (1986). Systematische montageplanung, Hanser, Munich (in German)

[3] Evans, S. M.; Chaffin, D. B. (1986). Using interactive visual displays to present ergonomic information in workplace design, Trends in ergonomics/human factors III, 17-24

[4] Edward, K. K (1970). A model for the design of manual work stations, PhD Dissertation, University of Michigan

[5] Beevis, D. (1989). Workplace design-anthropometrical and biomechanical approaches, Applications of human performance models to system design, 327-339

[6] Dooley, M. (1982). Anthropometric modelling programs: A survey, Computer graphics and application, New York: Institute of Electrical and Electronic Engineering (IEEE), Vol. 2, No. 6, 17

[7] Abdel-Moty, E.; Khalil, T. M. S. (1986). Computer aided design of the sitting workplace, Computer and Industrial Engineering, Vol. 11, No. 1-4, 22-26

[8] Brennan, L.; Farrel, L.; McGlennon, D. (1990). ERGOSPEC: A prototype expert system for workstation design, Computer-aided ergonomics, 117-127

[9] Feranandez, J. E.; Marley, R. J., Eyada, O. K. (1990). ErgoCAD: An ergonomic CAD system, Computer and Industrial Engineering, Vol. 18, No. 3, 313-318 
[10] Haller, E. (1982). Rechnergestutzte Gestaltung ortsgebundener Montagearbeitsplatze, dargestellt am Beispiel kleinvolumiger Teile, IPA Forschung und Praxis, Springer, Berlin

[11] Ho, N. C.; Lim, T. E. (1990). Computer-aided workplace layout and line balancing, Karwowski, W. A.; Genaidy, M.; Asfour; S. S. (Editors), Computer-aided ergonomics: A researcher's guide, Taylor \& Francis, New York

[12] Zhaa, X. F; Limb, S. Y. E. (2003). Intelligent design and planning of manual assembly workstations: A neuro-fuzzy approach, Computers \& Industrial Engineering, Vol. 44, 611- 632

[13] Eklund, J. (1997). Ergonomics, quality and continuous improvement-conceptual and empirical relationships in an industrial context, Ergonomics, Vol. 40, 982-1001

[14] Bunning, T. (1998). Designing ergonomically sound assembly workstations, Occupational Hazards, Vol. 60, No. 8, 63-65

[15] Larson, M. (1998). Ergonomic workstations boost productivity, Quality, Vol. 37, No. 3, 44-54

[16] Zeffane, R. (1994). Job satisfaction and workredesign: findings from Australia, International Journal of Comparative Sociology, Vol. 35, 137-141

[17] Das, B.; Grady, R. M. (1983). Industrial workplace layout design: an application of engineering anthropometry, Ergonomics, Vol. 26, No. 5, 433-447

[18] Hertzberg, H. T. E. (1972). Engineering anthropology, Human Engineering Guide to Equipment Design, Revised Edition, McGraw- Hill, New York

[19] Farley, R. R. (1955). Some principles of methods and motion study as used in development work, General Motors Engineering Journal, Vol. 2, No. 6, 20-25

[20] Squires, P. C. (1956). The shape of the normal working area, Report No. 275, US Navy Department, Bureau of Medicine and Surgery, Medical Research Laboratories, New London, Connecticut

[21] Konz, S.; Goel, S. C. (1969). The shape of the normal work area in the horizontal plane, AIIE Transactions, Vol. 1, No. 1, 70-74

[22] Das, B.; Behara, B. N. (1995). Determination of the normal horizontal working area: a new model and method, Ergonomics, Vol. 38, No. 4, 734-748

[23] Sengupta, A. K.; Das, B. (2000). Maximum reach envelope for the seated and standing male and female for industrial workstation design, Ergonomics, Vol. 43, No. 9, 1390-1404

[24] Jung, E. S.; Park, S. J. (1994). Prediction of human reach posture using a neural network for ergonomic man models, Computer and Industrial Engineering, Vol. 27, No. 1-4, 369-372

[25] Lim, S. Y. E.; Fok, S. C.; Tan, I. T. Y. (1996). Neural network investigation of posture and motion, Robertson, S. A. (Editor), Contemporary ergonomics, Taylor \& Francis, New York, $539-544$

[26] Zha, X. F.; Lim, S. Y. E.; Fok, S. C. (1998). Integrated intelligent design and assembly planning: A survey, International Journal of Advanced Manufacturing Technology, Vol. 14, No. 9, 664685

[27] Jung, E. S.; Freivalds, A. (1990). Development of an expert system for designing workplaces in manual material handling jobs, Karwowski, W.; Genaidy, A. M.; Asfour, S. S. (Editors), Computer-aided ergonomics: A researcher's guide, Taylor \& Francis, New York, 279-298

[28] Rombach, V.; Laurig, W. (1990). ERGON-EXPERT: A modular knowledge-based approach to reduce health and safety hazards in manual materials handling tasks, Karwowski, W.; Genaidy, A. M.; Asfour S. S. (Editors), Computer-aided ergonomics: A researcher's guide, Taylor \& Francis, New York, 299-309

[29] Karhu, O.; Kansi, P.; Kuirinka, I. (1977). Correcting work postures in industry: a practical method for analysis, Applied Ergonomics, Vol. 8, 199-201

[30] Mahone, D.; CNA Insurance Companies, Chicago IL, Corporate Underwriting Center, Ergonomics in the Textile and Apparel Industries, http://toolboxtopics.com/Beyond\%20Safety\%20Meetings/Power\%20Points/Ergonomics\%20in\%2 0the\%20Textile\%20Industry.PPT, accessed on 06.10.2004 